\title{
BRIDGING COASTAL RESEARCH PROGRAMS BETWEEN INDONESIA AND JAPAN
}

\author{
Zainal Arifin $^{1 *}$ and Hiroaki Saito ${ }^{2}$ \\ ${ }^{1}$ Research Center for Oceanography, Indonesian Institute of Sciences (LIPI). Jakarta, Indonesia. \\ ${ }^{2}$ Atmosphere and Ocean Research Institute, The University of Tokyo. Kashiwa, Japan. \\ *Correspondence author: <zain003@lipi.go.id>
}

Received: May 2019 Accepted: June 2019

\begin{abstract}
The JSPS Core-to-Core Research and Education Network on Coastal Ecosystems in Southeast Asia (RENSEA) 2016-2019 program has benefited Indonesian and Japanese researchers, as well as researchers in Southeast Asia. The program consists of three research groups; G1: Physical oceanography, G2: Biodiversity, and G3: Marine pollution. Considering the vast geographical area of Indonesia, managing joint research at the national level is challenging. Few active members, lack of funding, as well as the reorganization of research institutions over the last two years, pose more challenges. Funding as an engine of research execution has become highly competitive in recent years; therefore, research groups need to be more active in securing available funding at the national level, such as the COREMAP-CTI demand-driven research program, LPDP research scheme, and INSINAS research fund. From the science management perspective, the regional Core-to-Core RENSEA program needs to adapt to global trends in marine science with closer communication during the planning and execution of research projects. We recommend that joint research projects are developed to have more joint supervisory of graduate students; therefore, the collaboration would result in joint research publications and formal degrees for young scientists at the end of the program. In this way, the JSPS Core-to-Core program would have more significant benefits to the development of coastal science and research cooperation.
\end{abstract}

Keywords: Coastal research, collaboration, JSPS Core-to-Core, Indonesia, Japan.

\section{INTRODUCTION}

The rich characters of Indonesian coastal areas from the western to eastern Indonesia produce thriving marine life and biodiversity. Indonesian archipelagic area stretches a vast area between Weh Island in the western tip of Indonesia and Kolepom Island in the east. Shallow waters dominate the western part of Indonesia where islands typically have flat sea-shore contour. This is in contrast with steep coastal areas with drop off in eastern Indonesia with its deep-sea waters. Most Indonesian islands are dominated by three main coastal ecosystems, which are coral reefs, mangroves, and seagrass meadows.
At a wider regional scale, the high biodiversity region extends to the north along the Kuroshio Current, the western boundary current of the North Pacific Ocean (Fujikura et al., 2010) that reaches to Japan. The Kuroshio transports various marine organisms from the Coral Triangle to the north (Saito, 2019) and the organisms have adapted to the environment of Japanese waters and differentiated to new species and/or obtained unique morphological and physiological characteristics (e.g., Veron et al., 2009; Kuriiwa et al., 2014). Therefore, Japanese waters could help to understand how species dispersed, evolved, and environmental control factors on biodiversity. 
In particular, coastal areas in eastern Indonesia have been of great interest. From naturalists' perspectives, several well-known scientists such as Alfred Wallace and George E. Rumphius have recognized that the eastern Indonesian sea as very productive, the center of marine biodiversity, the center of marine species origin and center of species endemism. The area is known as the Coral Triangle area that includes six countries, i.e., the Philippines, Malaysia, Indonesia, Timor Leste, Papua New Guinea, and the Solomon Island (Figure 1). The highly productive eastern Indonesian waters support fishing. When Japanese overseas fishery was developed in the region in the late 1920s, the first base of fishing fleets for skipjack tuna fishery was established in Ambon in 1932. From the period, it has been a long history of collaboration in fisheries between Indonesia and Japan.

Based on mutual scientific interests, Indonesia and Japanese researchers have been conducting collaborative programs throughout the years. The Cooperative Study of the Kuroshio and Adjacent Regions (CSK) program during 1965-1979 led by the Intergovernmental
Oceanographic Commission (IOC) was the first collaborative ocean study. From 2001, several projects supported by Japan Society for the Promotion of Science (JSPS) have been carried out continuously and accelerated marine science collaboration between Indonesia and Japan. Both countries are part of the JSPS Core-to-Core RENSEA (Research and Education Network on Coastal Ecosystems in Southeast Asia) program with various joint studies. The program consists of three research groups, i.e., G1: Physical oceanography, G2: Biodiversity, and G3: Marine pollution. JSPS coastal research program has evolved from bilateral cooperation to multilateral cooperation. The program has a long-standing record for nurturing a network of scientists not only between Japanese and Indonesia but also among marine science scientists in Southeast Asia.

The objective of the present paper is firstly to review the JSPS Core-to-Core RENSEA program between Indonesian and Japanese scientists. And secondly, to propose a new scheme of the JSPSLIPI collaboration on coastal research to improve the research network in the near future.

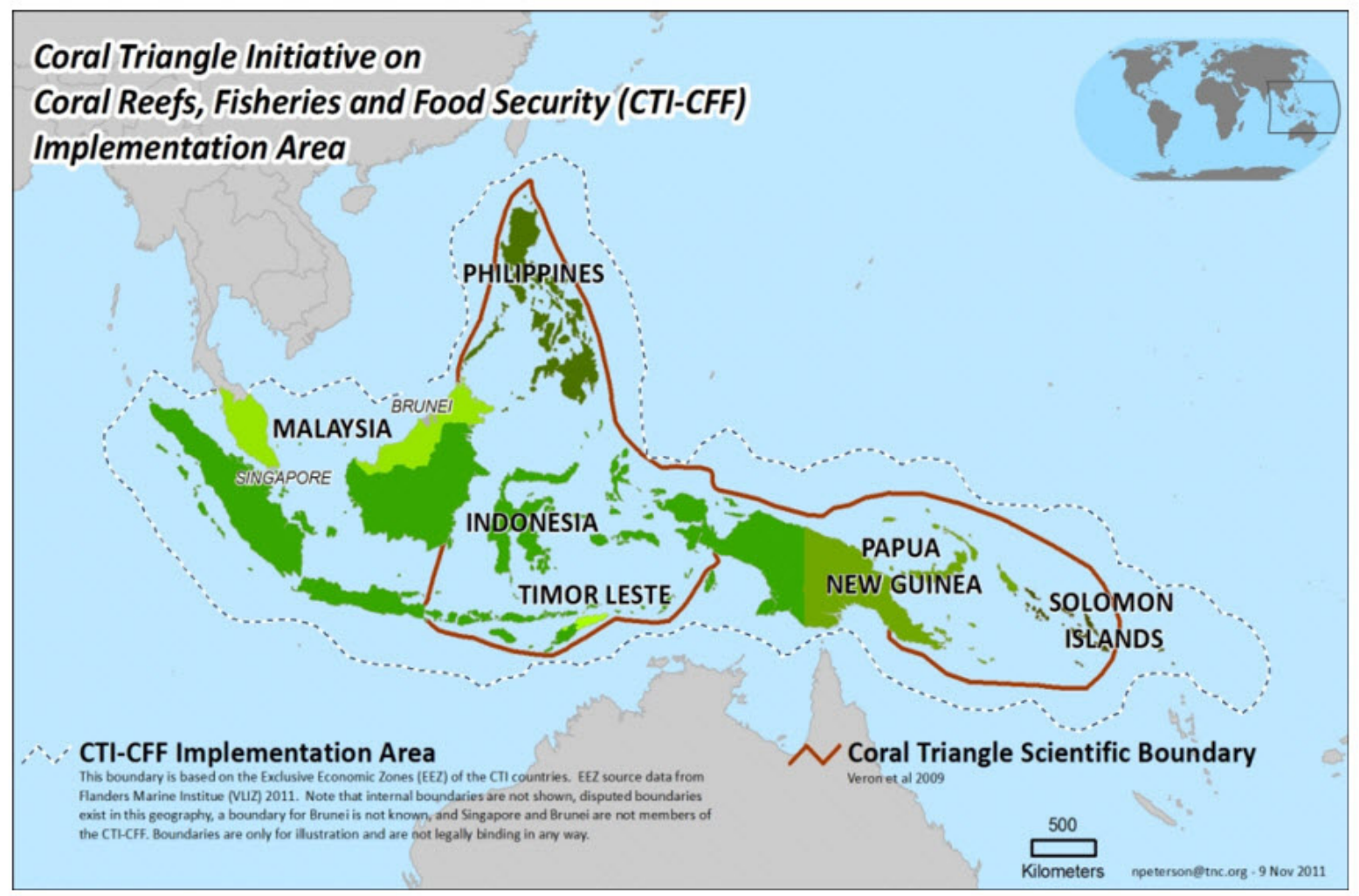

Figure 1. Map of Indonesia coincides with the area of Coral Reefs, Fisheries and Food Security (CTI-CFF) Implementation Area. Source: mission-blue.org. 


\section{Current Program on Coastal Research}

The JSPS Core-to-Core RENSEA program has 43 members from Indonesia, consisting of 7 researchers from Group 1 (Physical oceanography), 31 researchers from Group 2 (Biodiversity) and 5 researchers from Group 3 (Marine pollution). The researchers belong to five research institutions and six universities (e.g., Universitas Maritim Raja Ali Haji, Universitas Indonesia, Institute Pertanian Bogor, Institut Teknologi Bandung, Universitas Hasanuddin, Universitas Sam Ratulangi). Three current projects under the program include hydro color technology, marine biodiversity, and medaka projects. The hydro color technology utilizes a smartphone application using for coastal monitoring to increase fishers' knowledge of the management of coastal environments and fishery resources for sustainability. The biodiversity group has various topics such as fish, plankton, harmful algal bloom (HAB), macrophyte, and benthos. The medaka project uses medaka fishes as a bioindicator of pollution.

There are several challenges facing the program in recent years. The program suffers from low numbers of active researchers and outputs. The most active project among the biodiversity group is the ecology of HAB. While the medaka bioindicator project in Indonesia still lags compared to, for example, Malaysia. Out of the 43 researchers, only a few members have active collaborations with their regional partners while most involve only at the annual seminar (Figure 2). The number of active Indonesian scientists who publish their works is only about one-third of the total number of members. This low output of research could be due to unclear research theme and/or lack of research roadmap.

Moving forward, there are at least three issues that needed to be reformed for the program. First, there is a need to redesign research activities and management of projects by linking them to national programs to gain more funding support and have broader scientific impacts. The current program is excellent in term of scientific development, but it does not provide a broad and significant impact on society and with no involvement of the local government. Second, there should be themes of research that encourage Indonesian researchers across research groups to work together in solving coastal issues.

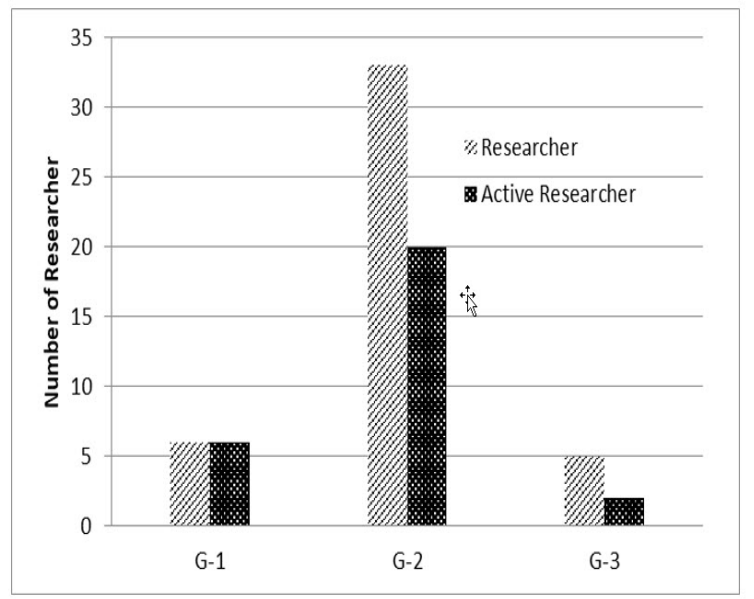

Figure 2. Number of Indonesian researchers under the JSPS Core-to-Core RENSEA program.

G1: Physical Oceanography, G-2: Biodiversity, and G-3: Marine Pollution.

Third, closer scientific communication is needed between Indonesian and Japanese researchers on research topics. For example, the biodiversity research group has a wide range of topics from biosystematics to ecological research where the Japanese researchers focus on biosystematics, while Indonesian researchers mostly work on ecological research.

\section{New Direction for Coastal Research Program}

The JSPS Core-to-Core-RENSEA program needs fundamental changes in conducting research cooperation to adapt to the regional and global trends in marine science. The design of research should be discussed openly at the initial stage of research cooperation, especially on research themes, duration of research, and involved scientists.

The theme of research is an essential guiding agenda to involve current and new researchers. Research themes need to be as much as possible in line with both global (e.g., linked to the Decade of Ocean Science; UNESCO, 2017) and national programs. For instance, the Coordinating Ministry of National Planning (BAPPENAS) coordinates the SDG 2030 program in Indonesia. This approach could help researchers to secure funding. Funding is the engine of our activities as a group, and individual scientists should secure funding from various resources. At the national 
level, there are several schemes for research funding, among others, LPDP and INSINAS research funds.

The duration of the research program should be a reasonable time, three years with consideration for an extension to a maximum of five years. The program could have more impacts by approaching local governments, marine resource managers, industries, and stakeholders during the planning of the research program when applicable. Issues such as trends in regional biodiversity from higher latitude (Japan) to the tropics, multi-stressors due to anthropogenic activities (e.g., climate change, eutrophication, oil spill, mining, pesticide pollution) on coastal ecosystems, could answer how multiple stresses affect ecosystem health.

Another potential research program is to develop a multidisciplinary research program consisted of physical, chemical, and biological aspects of the ecosystem and link with socioeconomic studies. Currently, the JSPS Coreto-Core coastal research program runs based on each research group; therefore the programs are driven by individual scientists. We suggest that the new JSPS program in Southeast Asian focuses on the development of a research plan through workshops or group discussions. The locus of work should also consider through cooperation with the local governments, national scientists, and industries. Linking our research program with the local government interest will benefit both parties; the scientists help in identifying the most urgent issues, while local communities through the local government will benefit from the output of research. The JSPS new scheme program will attract more potential scientists to join when the new scheme is clearly described.

Some potential study sites include Weh Island in the western tip of Indonesia or Bintan Island in the Strait of Malacca, South Sulawesi in the middle of Indonesia, Lombok Island on the Indian Ocean side and Manado that faces the Pacific Ocean (Figure 3). Weh Island is located at the meeting point between the Andaman Sea, Malacca Strait and the Indian Ocean that are crucial for fishing industries, energy trades, marine tourism, and shipping. From the northern tip to its south end, Sulawesi Island is at the eastern border of Wallace Line with unique marine and terrestrial biodiversity. Lombok Island and the Lesser Sunda Islands to its east provide an opportunity to study how the Indian Ocean and the Indonesian Throughflow influence the dynamics of marine resources in the region.

Marine science is in the growing stage in Indonesia, particularly with the current presidential vision to become the world's

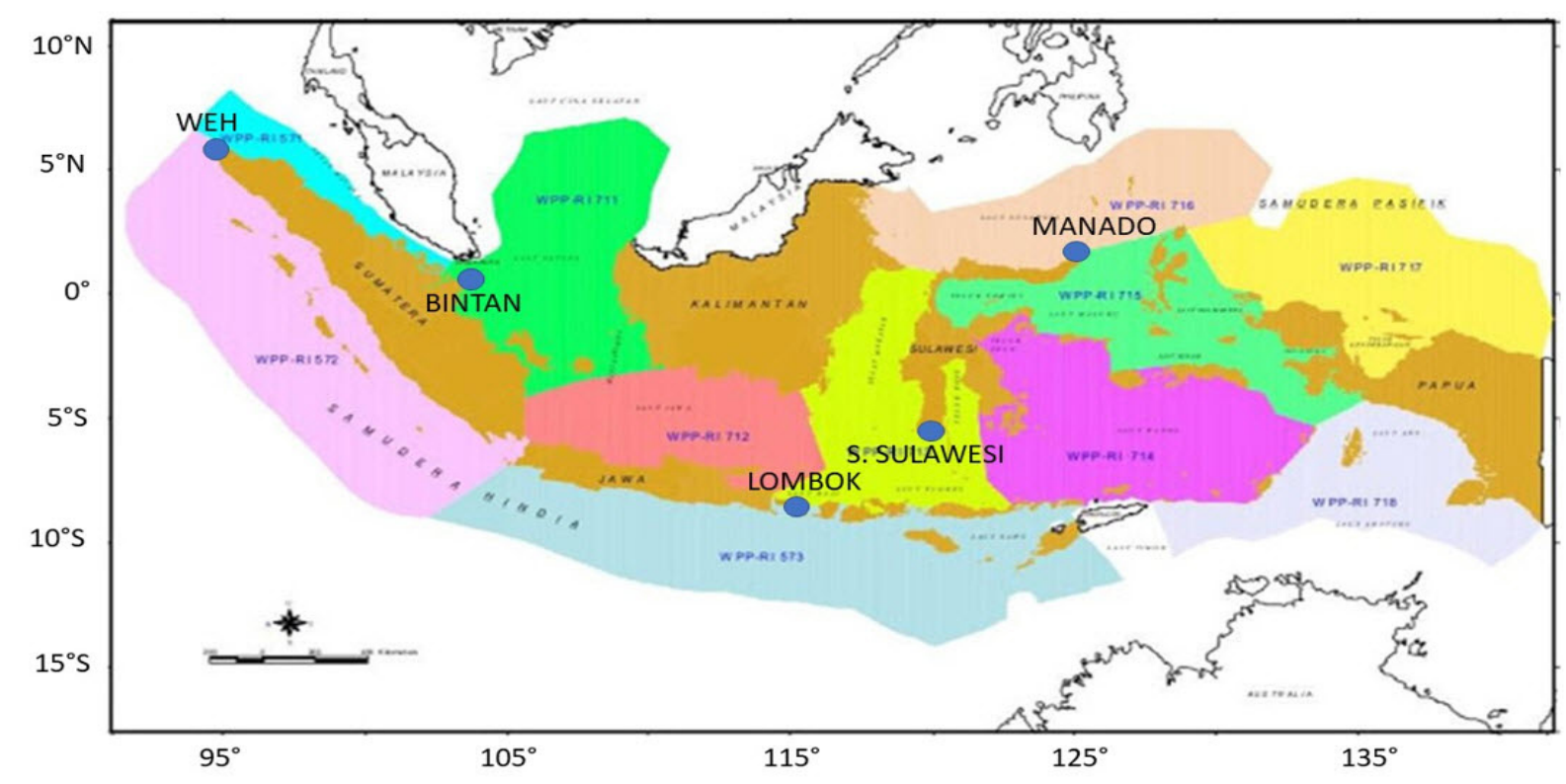

Figure 3. Potential sites for a new scheme of research cooperation within the context of fisheries management areas in Indonesia. 
maritime fulcrum. Marine science is one of the eight national priority research themes for 2015 - 2045, which are 1) Food, 2) Energy, 3) Health, 4) Transportation, 5) Engineering, 6) Security, 7) Maritime, and 8) Social and Humanity (Ministry of S\&T and High Education, 2017). Marine science, including oceanography and marine biodiversity, falls within the Maritime theme. Two ongoing national coastal research programs are Coral Reef Rehabilitation and Management Program to support coral triangle initiative (COREMAP-CTI) and marine plastic pollution program (Presidential Decree, 2018; MoEF, 2019). For periods 2017-2022, COREMAP-CTI focuses on monitoring the health of and research on coral reefs, mangroves, and seagrass meadows. COREMAP-CTI also funds a demand-driven research program scheme on coastal ecosystems health. The second research priority is on marine plastic pollution for the period 2020-2025 with three research areas: 1) understanding the effects of marine plastic pollution on marine organisms, 2) understanding the effects of microplastics on human health, and 3) research and innovation on developing plastic substitutes (MoEF, 2019). Both COREMAP-CTI and marine plastic pollution programs are potential for collaborative research between Indonesian and Japanese researchers in the near future.

\section{SUMMARY}

In summary, to foster a new scheme of research cooperation, we identify the need to update with and find new approaches to answer frontier scientific problems that concurrently meet societal needs. The new scheme of JSPS Indonesia should focus on coastal science where most marine resources are harvested from in the region, and our prosperous society depend on a sustainable supply of ecosystem services.

\section{ACKNOWLEDGMENT}

We want to thank all members of Japanese and Indonesian scientists who have contributed to the development of coastal marine science in Indonesia. We thank Prof. Nishida for his continuous support to the Core-to-Core RENSEA program. We also thank Prof. Syachoemar and Ms. Toha for their assisting activities at the national level, and Ms. Hesti for assisting in the preparation of the figures. This paper was presented at the Third Core-to-Core-RENSEA Joint Seminar on Coastal Ecosystem in Southeast Asia in Bangkok. The travel cost was partly funded by JSPS and LIPI.

\section{REFERENCES}

Fujikura, K., Lindsay, D., Kitazato, H., Nishida, S., and Shirayama, Y., (2010). Marine biodiversity in Japanese waters. PLoS ONE, 5, e11836. doi:10.1371/journal.pone.0011836.

Kuriiwa, K., Chiba, S.N. Motomura, H., and Matsuura, K (2014). Phylogeography of blacktip grouper, Epinephelus fasciatus (Perciformes: Serranidae), and influence of the Kuroshio Current on cryptic lineages and genetic population structure. Ichthyol. Res., 61(4), 361-374, doi:10.1007/s10228-0140408-9.

MoEF. (2019). Implementation of national action plan on management of marine litters. Ministry of Environment and Forestry (MoEF), RI. (pp. 30).

MoS\&T and Higher Education. 2017. National Research Plan 2017 - 2045. Kementerian Riset dan Teknologi dan Pendidikan Tinggi (MoS\&T and Higher Education). Jakarta. (pp. 96).

Presidential Decree. (2018). National action plan on marine plastic pollution. Presidential regulation on handling marine litter. PerPres RI no 83/2018. (pp. 10).

Saito, H. (2019). The Kuroshio: Its recognition, scientific activities and emerging issues. In: Kuroshio Current: Physical, Biogeochemical, and Ecosystem Dynamics, T. Nagai, H. Saito, K. Suzuki, M. Takahashi (ed). American Geophysical Union. doi: 10.1002/9781119428428.ch1. 